\title{
Concise Approach for Determining the Optimal Annual Capacity Shortage Percentage using Techno- Economic Feasibility Parameters of PV Power System
}

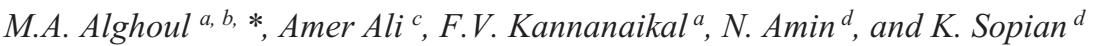 \\ ${ }^{a}$ Energy and Building Research Center, Kuwait Institute for Scientific Research, Safat 13109, Kuwait \\ ${ }^{b}$ Center of Research Excellence in Renewable Energy (CoRe-RE), Research Institute, King Fahd University of \\ Petroleum and Minerals (KFUPM), Dhahran 31261, Saudi Arabia \\ ${ }^{c}$ The School of Applied Physics, Faculty of Science and Technology, Universiti Kebangsaan Malaysia \\ ${ }^{d}$ Solar Energy Research Institute, Universiti Kebangsaan Malaysia, 43600 Bangi, Selangor, Malaysia \\ *Corresponding author e-mail: dr.alghoul@gmail.com
}

\begin{abstract}
:
PV power systems have been commercially available and widely used for decades. The performance of a reliable PV system that fulfils the expectations requires correct input data and careful design. Inaccurate input data of the techno-economic feasibility would affect the size, cost aspects, stability and performance of PV power system on the long run. The annual capacity shortage is one of the main input data that should be selected with careful attention. The aim of this study is to reveal the effect of different annual capacity shortages on the techno-economic feasibility parameters and determining the optimal value for Baghdad city location using HOMER simulation tool. Six values of annual capacity shortage percentages $(0 \%, 1 \%, 2 \%, 3 \%, 4 \%$, and $5 \%)$, and wide daily load profile range (10 kWh - $100 \mathrm{kWh}$ ) are implemented. The optimal annual capacity shortage is the value that always "wins" when each techno-economic feasibility parameter is at its optimal/ reasonable criteria. The results showed that the optimal annual capacity shortage that reduces significantly the cost of PV power system while keeping the PV system with reasonable technical feasibility is $3 \%$. This capacity shortage value can be carried as a reference value in future works for Baghdad city location. Using this approach of analysis at other locations, annual capacity shortage can be always offered as a reference value for those locations.
\end{abstract}

Keywords: PV power system, effect of different annual capacity shortages, techno-economic feasibility parameters, HOMER simulation tool, optimal annual capacity shortage

\section{INTRODUCTION}

Renewable energy (RE) power systems are rapidly gaining popularity as alternative energy source [1-3]. Photovoltaic has been identified as one of the promising solar technologies to replace the dependency on other conventional energy resources. The performance of a reliable PV power system that fulfils the expectations requires correct input data and careful design. Inaccurate input data when predicting the techno-economic feasibility would affect system cost, size and performance of PV power system on the long run. HOMER simulation tool was found to be one of the easiest and commonly used software [4]. It is widely used in designing solar PV power systems [5-8] and wind power systems [9-11]. HOMER simulates a diverse range of micro-power system configurations and creates a comprehensive list of all possible system designs according to cost-effectiveness. The simulation process aids in selecting the most appropriate system, which is capable of providing electrical loads judiciously by calculating the life cycle cost of the system. Allowing for a small percentage of annual capacity shortage could reduce the system cost significantly. Therefore, this study aims to predict the optimum annual capacity shortage pertaining to Baghdad city location. To accomplish this objective, six values of annual capacity shortage $(0 \%, 1 \%$, $2 \%, 3 \%, 4 \%$, and $5 \%$ ) are implemented and tested versus load profile range (10 kWh - $100 \mathrm{kWh})$. The operating hours of the load is assumed from 8:00am-6:00pm.

\section{Materials and methods}

2.1. Study Evolution Methodology 


\begin{tabular}{|c|c|c|c|}
\hline $\begin{array}{l}\text { Input data/ } \\
\text { Components/ } \\
\text { Design scope }\end{array}$ & $\begin{array}{l}\text { Implemente } \\
\text { data: } \\
\text { Average so } \\
\text { different da } \\
\text { Implemente } \\
100 \mathrm{kWh}) \mathrm{f} \\
\text { Implemente } \\
(0,1,2,3,4\end{array}$ & $\begin{array}{l}\text { radiation input } \\
\text { ation from (4) } \\
\text { am to } 6: 00 \mathrm{pm} \\
\text { y shortage: }\end{array}$ & $\begin{array}{l}\text { Location of the study: Baghdad } \\
\text { Latitude }\left(33^{\circ}\right) \text {, Longitude }\left(44^{\circ}\right) \\
\text { PV Panel: (CS6X-295M, } 0.295 \mathrm{~kW} \text {, cost } 500 \\
\text { US\$, replacement cost } 436 \mathrm{US} \$) \\
\text { Battery type: ((RA12) 260Ah, } 12 \mathrm{~V} \text {, } \\
3.12 \mathrm{kWh} \text {, cost } 900 \mathrm{US} \$ \text {, replacement cost } \\
900 \mathrm{US} \$) \\
\text { Converter: capital and replacement costs } \\
\text { are } \$ 1095 / \mathrm{kW}\end{array}$ \\
\hline \multicolumn{4}{|c|}{ 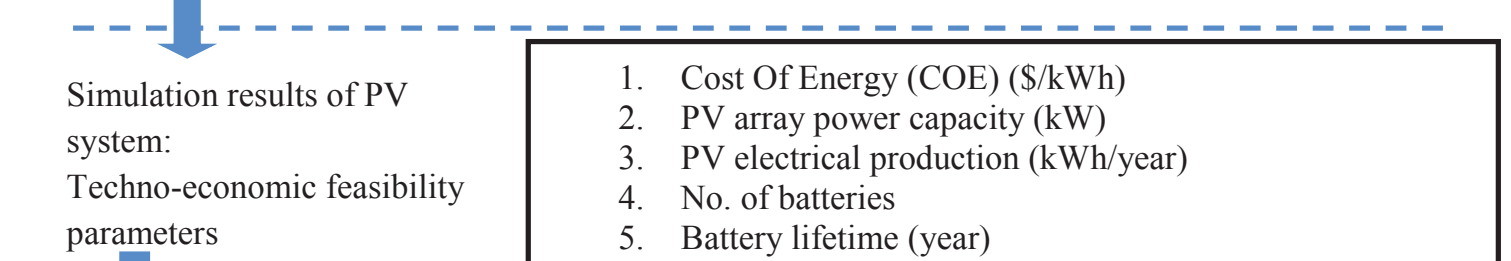 } \\
\hline $\begin{array}{l}\text { Research } \\
\text { objectives }\end{array}$ & $\begin{array}{l}\text { To } \\
\text { diff }\end{array}$ & $\begin{array}{l}\text { he the optimun } \\
\text { ues }(0 \%, 1 \%, 2 \%\end{array}$ & $\begin{array}{l}\text { ual capacity shortage percentage among } \\
4 \% \text {, and } 5 \% \text { ) }\end{array}$ \\
\hline
\end{tabular}

Fig. 1. Block diagram of the study evolution methodology

\subsection{Location of the study and solar irradiation data sources}

The present work is done for the location Baghdad, Iraq's capital located at $33^{\circ}$ latitude and $44^{\circ}$ longitude. The selected solar data sources are: Nasa climate site SRC1 [12], Weather base climate site SRC2 [13], meteorological department data (Iraq: 1984-2004) SRC3 [14] and meteorological department data (Iraq: 1962-1992) SRC4 [15]. Comparison between monthly solar radiations from different data sources indicates variation as illustrated in figure 2. Therefore, average monthly solar radiation from four data resources is adopted as an accurate input data in this study for Baghdad city.

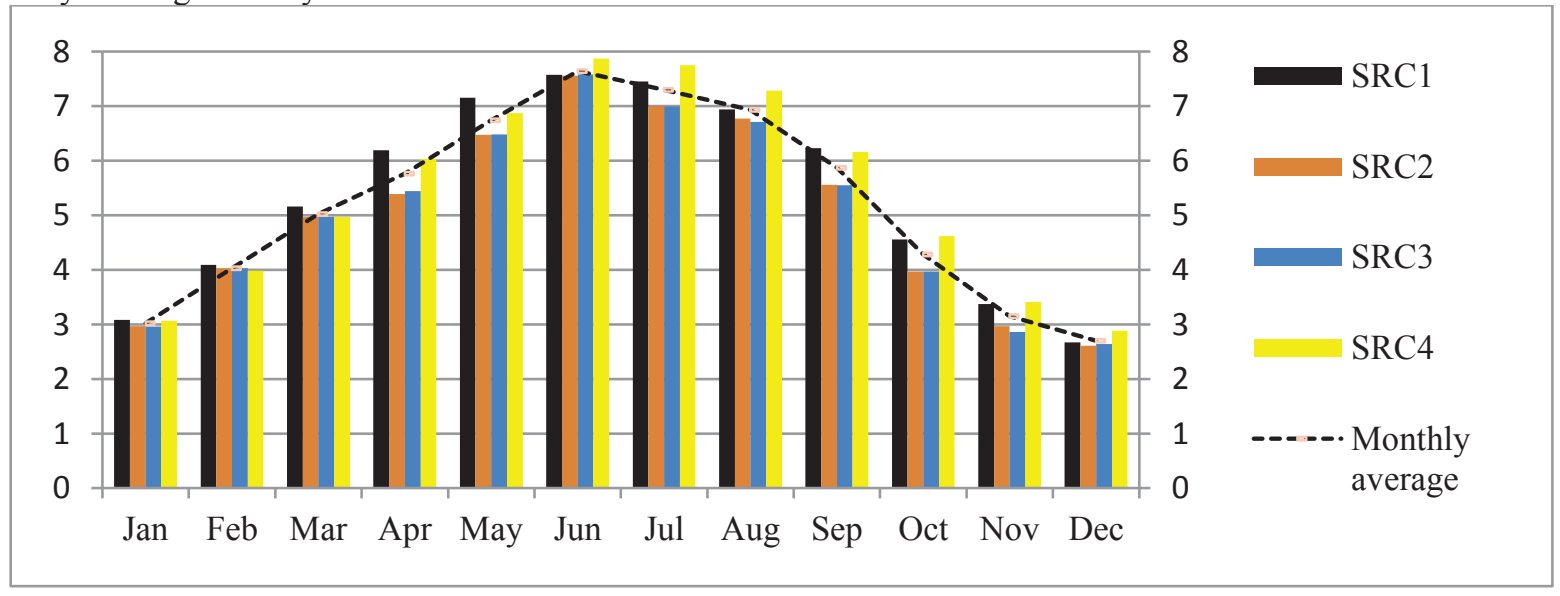

Fig. 2. Variation in solar radiation $\left(\mathrm{kWh} / \mathrm{m}^{2}\right)$ obtained from different data sources of Baghdad city, Iraq 


\section{SIMULATION RESULTS AND DISCUSSION}

The aim of this section is to determine the optimum annual capacity shortage to design a feasible PV power system for Baghdad city. In this course of analysis, percentages of reduction in the values of the main feasibility parameters at different annual capacity shortages were used as an evaluation tools. The decision on optimum annual capacity shortage value compare to other implemented capacity shortage values will be made based on the below set of criteria:

1. Reduction percentage of COE (maximum or approach to maximum)

2. Reduction percentage of PV Array power capacity (maximum or approach to maximum)

3. Reduction percentage of PV electrical production (minimum or approach to minimum)

4. Reduction percentage in No. of batteries (maximum or approach to maximum)

5. Reduction percentage in battery lifetime (minimum or approach to minimum)

Figures (3-7) illustrate the percentage of reduction in the values of techno-economic feasibility parameters versus daily load profile at different annual capacity shortages. As shown in Fig 3, the minimum percentage of reduction in the values of cost of energy $(\mathrm{COE})$ are observed at capacity shortages $(0 \%)$, followed by $(1 \%$ and $2 \%$ ) where their curves are almost overlapping each other versus the daily load. So, these capacity shortages will be ignored in this round of analysis. On the other hand, the maximum percentage of reduction in the values of COE is observed at capacity shortages ( 3 and 5\%), where their curves are mostly overlapping each other versus the studied daily load. However, to determine which of them is the most appropriate, it is essential to determine at which capacity shortage $(3 \%$ or $5 \%)$ the PV power system is technically most feasible and desired.

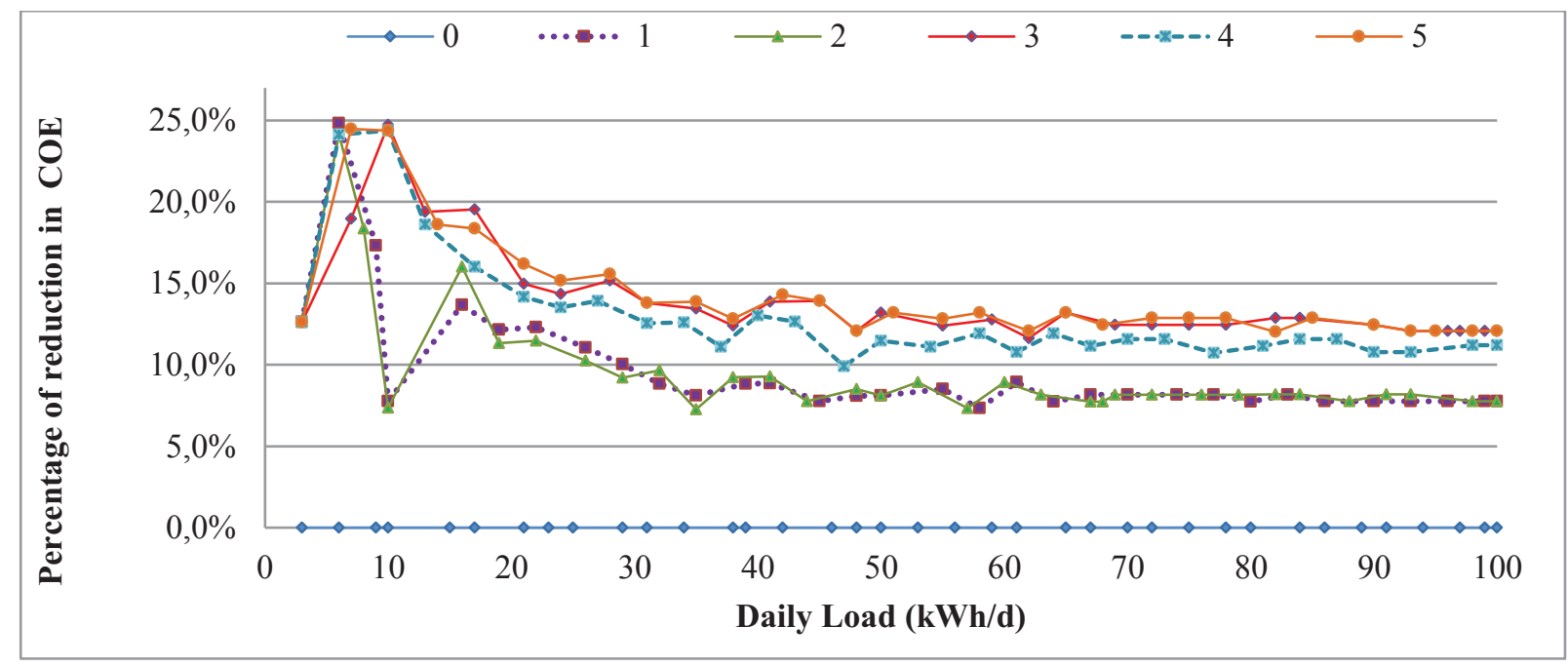

Fig. 3. Percentages of reduction in COE versus daily load profile at different annual capacity shortages

As shown in Fig 4, at the different capacity shortages, percentages of reduction in PV array power capacity are totally overlapping each other versus wide range of the studied daily load (at least $68 \%$ of the load range). However, lowest percentages of reduction are observed at capacity shortage value $4 \%$, followed by $0 \%, 1 \%$, and $5 \%$. Therefore, these capacity shortages will be ignored, because our criterion is maximum percentages of reduction. The maximum percentages of reduction are observed at capacity shortage value $2 \%$ versus daily load range (69-100) $\mathrm{kWh}$. Also, maximum percentages of reduction are observed at capacity shortage $3 \%$ versus very narrow range of 
daily load (98-100) $\mathrm{kW} /$ day. However, to decide which of them is the most appropriate (2\% or $3 \%$ ), it is essential to quantify at which capacity shortage, the percentage of reduction in PV electrical production is the minimum.

As shown in Fig 5, under the wide range of daily load, the capacity shortage values that show high percentages of reduction in PV electrical production are $(2 \%, 4 \%$, and $5 \%)$. So, these capacity shortages will be ignored in this round of analysis. On the other hand, the preferable low percentage of reduction is observed at capacity shortage values $(0 \%, 1 \%$, and $3 \%)$. At capacity shortages $(0 \%$, and $1 \%)$, the PV power system is not economically the most feasible, so capacity shortage $3 \%$ wins in this round of analysis.

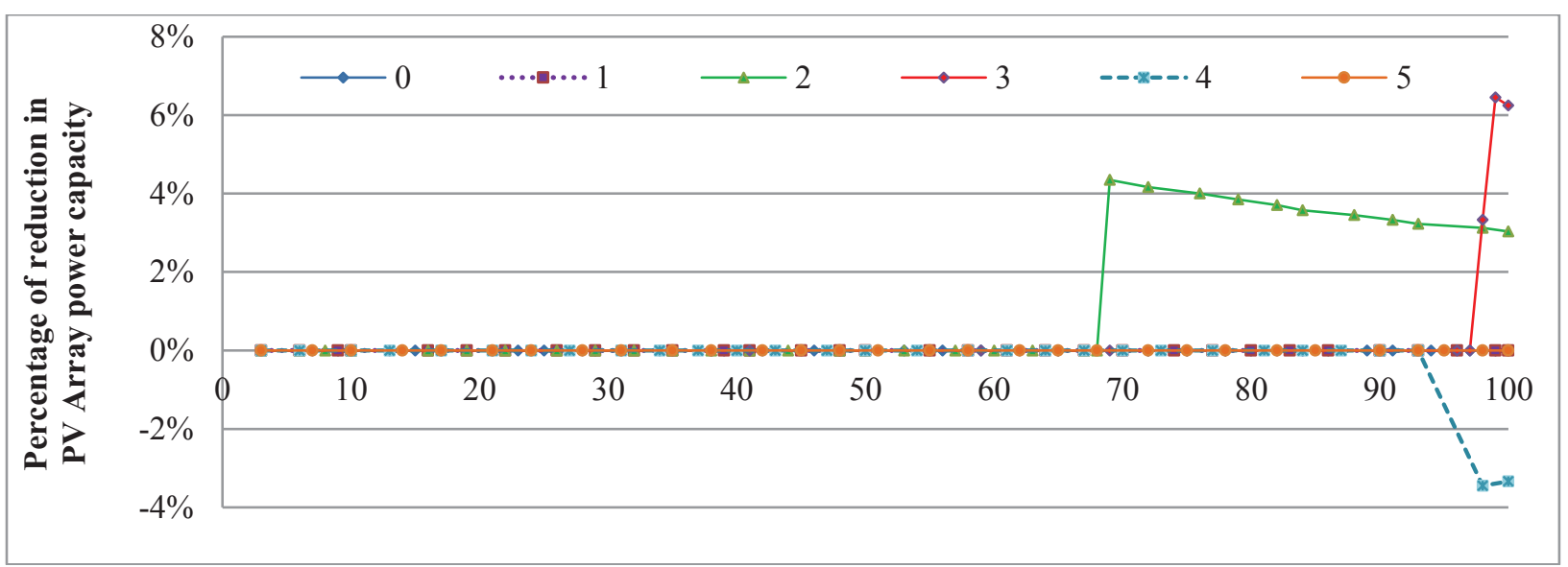

Fig. 4. Percentages of reduction in PV Array power capacity versus daily load profile at different annual capacity shortages.

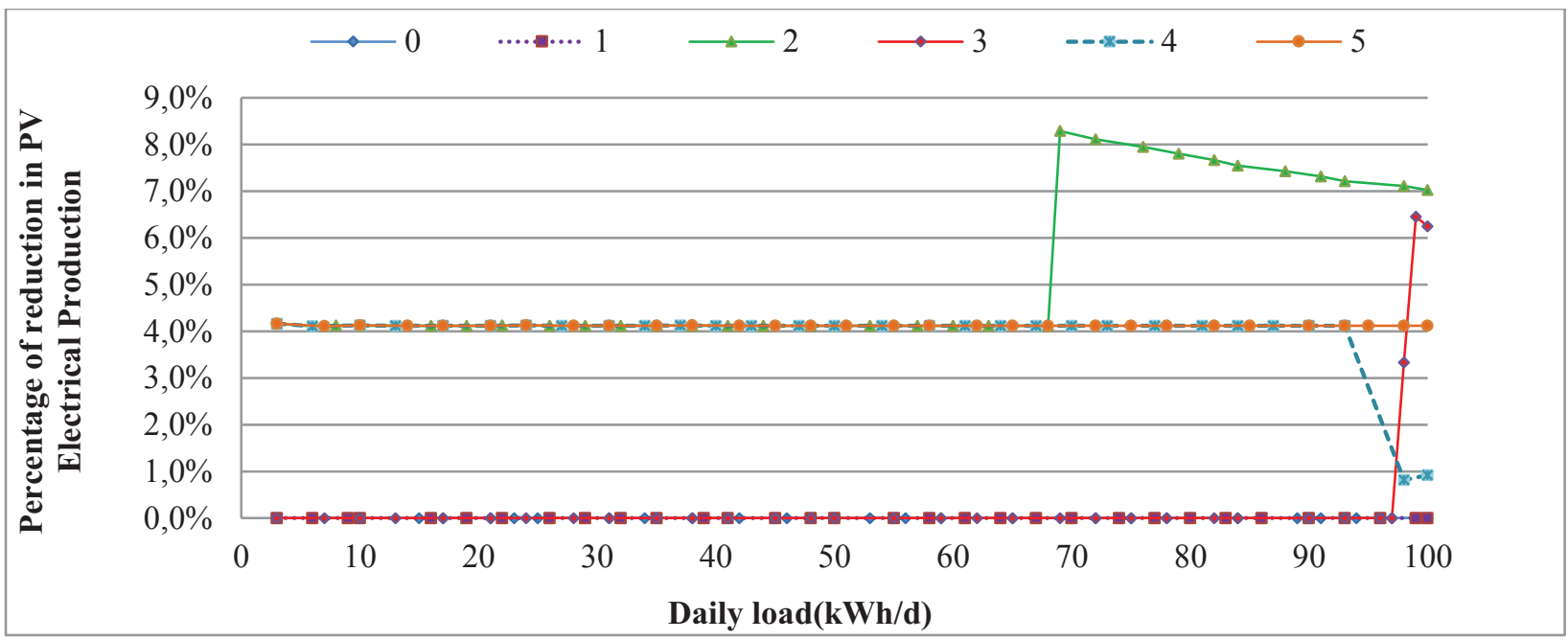

Fig. 5. Percentages of reduction in PV Electrical Production versus daily load profile at different annual capacity shortages.

As shown in Fig 6, under the wide range of daily load, the capacity shortage values that show minimum percentages of reduction in batteries number are $(0 \%$, and $1 \%)$. So, these capacity shortages are not desired and will be ignored. The maximum percentages of reduction in batteries number are found at $5 \%$ followed by $(2 \%$ or $3 \%$ or $4 \%$ ) depending on their trend versus the daily load. However, capacity shortages at ( $2 \%$ and $4 \%)$ will be ignored because the PV power system is not economically feasible. To decide which is the most appropriate capacity shortage $(3 \%$ or $5 \%$ ), it is essential to quantify at which capacity shortage, the percentages of reduction in battery life time is the minimum. 
As shown in Fig 7, under the wide range of daily load, the capacity shortage values that show maximum percentage of reduction in the values of battery bank life time are (5\% and 4\%). Since these high percentages are not desired, they will be ignored in this round of analysis. The minimum percentages of reduction in battery life time are at $0 \%$ followed by $1 \%$ and then by $3 \%$ or $2 \%$ depending on their trend versus the daily load. Since the PV power system is not economically feasible at capacity shortages $0 \%, 1 \%$ and $2 \%$ they will be ignored. So, the trustworthy value here is $3 \%$.

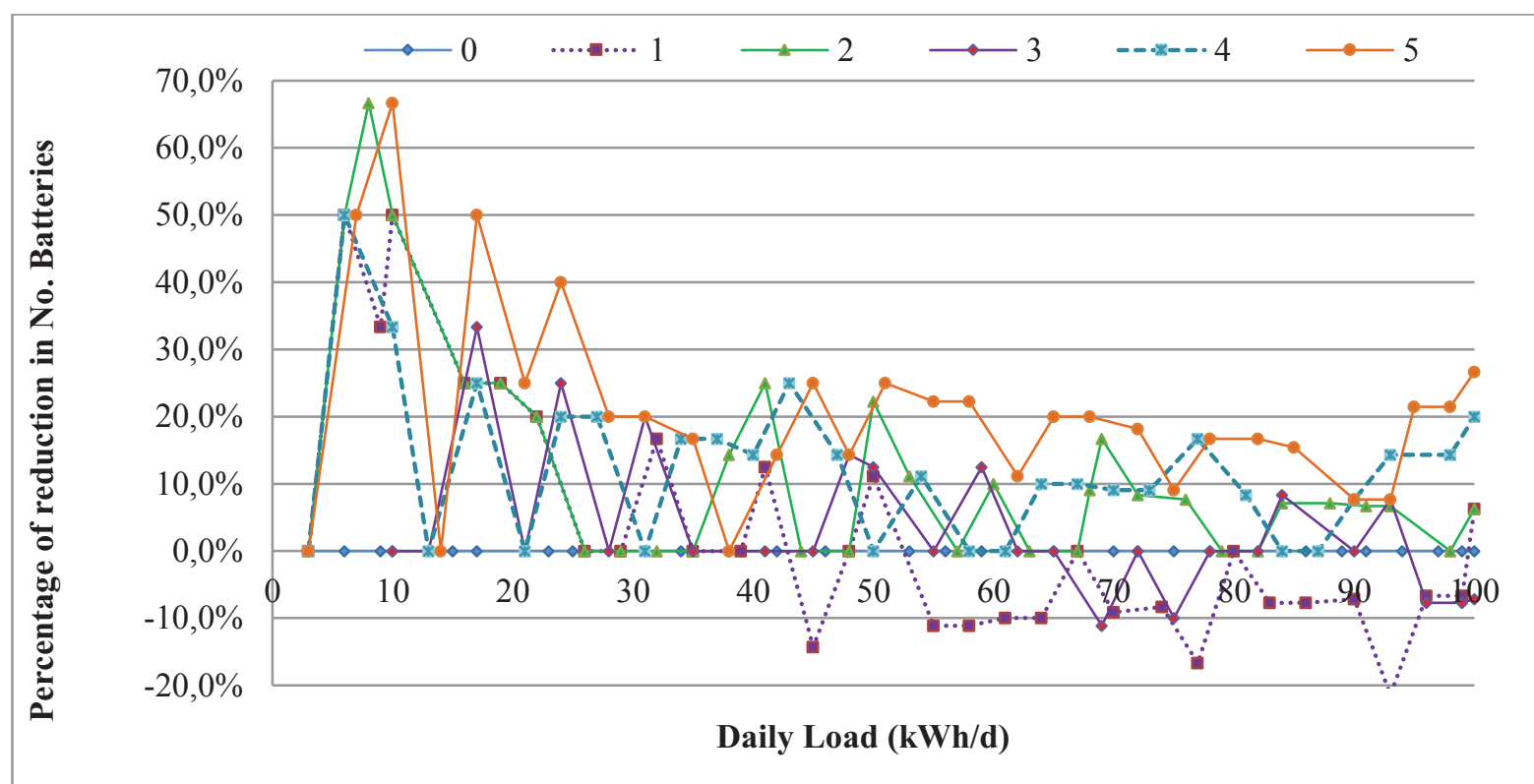

Fig. 6. Percentages of reduction in No. batteries versus daily load profile at different annual capacity shortages.

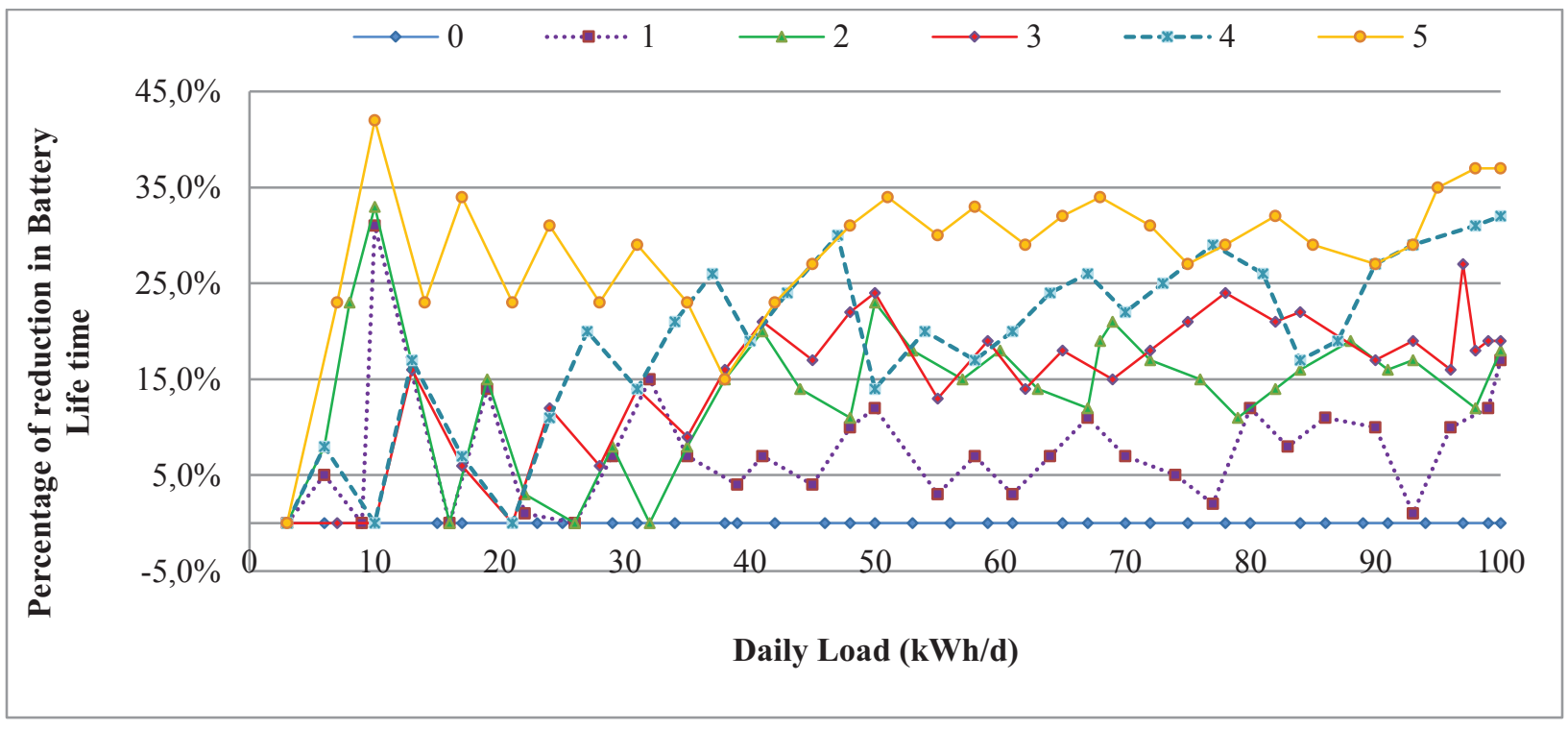

Fig. 7. Percentage of reduction in the values of battery bank life time versus daily load profile at different annual capacity shortages. 
Finally, based on the results learned from Figures 3 to 7 , it can be concluded that annual capacity shortage $3 \%$ is the most recommended value. Therefore, this value can be adopted as a reference annual capacity shortage in future works for designing PV power systems at Baghdad city location.

\section{CONCLUSION}

The outcome of this study is the followings:

1. Reaching the best economic feasibility of PV power system without affecting significantly the technical performance of the system is possible by adopting annual capacity shortage between $(0 \%-5 \%)$.

2. In this study, the results revealed that the optimum annual capacity shortage versus wide load profile range $(10-100 \mathrm{kWh} /$ day) for Baghdad city location is $3 \%$. This value can be recommended as a reference capacity shortage value when designing PV power systems in Baghdad city location.

3. It is recommended to broaden the analysis further by evaluating partial values of annual capacity shortage such as $(0.5 \%, 1.5 \%, 2.5 \%, 3.5 \%$, and $4.5 \%)$ to reach the most accurate value of annual capacity shortage.

4. Using this approach of analysis at other locations, annual capacity shortage would be offered as reference values in future works in those locations.

\section{REFERENCES}

[1] Goodbody, C., Walsh, E., McDonnell, K. P. \& Owende, P. 2012. Regional integration of renewable energy systems in Ireland - The role of hybrid energy systems for small communities. Electrical Power and Energy Systems 44: 713-720.

[2] Chowdhury, S. H. \& Oo, A. M. T. 2012. Study on electrical energy and prospective electricity generation from renewable sources in Australia. Renewable and Sustainable Energy Reviews 16: 6879-6887.

[3] Aagreh, Y. \& Al-Ghzawi, A. 2012. Feasibility of utilizing renewable energy systems for a small hotel in Ajloun city, Jordan. Applied Energy 103: 25-31.

[4] National Renewable Energy Laboratory, USA. Hybrid Optimization Model for Electric Renewables (HOMER). http://www.homerenergy.com/.

[5] Shaahid, S.M \& Elhadidy, M.A.2005. Economic analysis of hybrid photovoltaic-diesel-battery power systems for residential loads in hot regions-A step to clean future. Renewable and Sustainable Energy Reviews11: 635-653.

[6] Shaahid, S.M. \& Elhadidy, M.A. 2006. Technical and economic assessment of grid-independent hybrid photovoltaic-diesel-battery power systems for commercial loads in desert environments. Renewable and Sustainable Energy Reviews 11: 1794-1810.

[7] Malika Amini .2010. Renewable Energy Systems for Rural Health Clinics in Algeria: Homer Application. Energy 14: 1120-1130. http://homerenergy.com/webcast-downloads/Malika_Amini/health.pdf

[8] Widatalla, A.M. and Zinko, H., 2011, November. Designing a Photovoltaic Solar Energy System for a Commercial Building. Case Study: Rosa Park Hotel in Khartoum-Sudan. In World Renewable Energy Congress-Sweden; 8-13 May; 2011; LinkÃ ping; Sweden (No. 057, pp. 2899-2906). Linköping University Electronic Press.

[9] Osorio, L., Velo, R., Fernández, M. D. \& Rodríguez, M. R. 2012. Feasibility of the electrical supply by wind power in dairy cattle farms. International Conference of Agricultural Engineering, Valencia, July 2012.

[10] Adaramola, M. S. 2012. Feasibility study of off-grid hybrid energy systems for applications in Ondo State, Nigeria. Journal of Engineering and Applied Sciences 7(1): 72-78.

[11] Fahmy, F. H., Ahmed, N. M. \& Farghally, H. M. 2012. Optimization of Renewable Energy Power System for Small Scale Brackish Reverse Osmosis Desalination Unit and a Tourism Motel in Egypt. Smart Grid and Renewable Energy 3: 43-50.

[12] https://eosweb.larc.nasa.gov/sse/RETScreen/

[13] www.weatherbase.com 
[14] Tadros, M. T. Y., Mustafa, M. A. M., \& Abdel-Wahab, M. 2014. Estimation of the Global Horizontal Solar Radiation in Iraq. International Journal of Emerging Technology and Advanced Engineering Website: www.ijetae.com (ISSN 2250-2459, ISO 9001:2008 Certified Journal, Volume 4, Issue 8, August 2014)

[15] Abdul-Wahid, S. N., \& Hassan, A. M. 2010. Calculation and applications of net solar radiation in Iraq. $J$ AlQadisiyah Pure Sci, 15, 1-30. 